\title{
The Role of Tubulointerstitial Inflammation in the Progression of Chronic Renal Failure
}

\author{
Bernardo Rodríguez-Iturbe a Guillermo García García ${ }^{b}$ \\ aServicio de Nefrología, Hospital Universitario de Maracaibo, Universidad del Zulia and Centro de Investigaciones \\ Biomédicas, Instituto Venezolano de Investigaciones Científicas (IVIC-Zulia), Maracaibo, Venezuela; \\ bServicio de Nefrología, Antiguo Hospital Civil de Guadalajara, Centro Universitario de Ciencias de la Salud, \\ Universidad de Guadalajara, Guadalajara, Mexico
}

\section{Key Words}

Inflammatory cells $\cdot$ Proteinuria $\cdot$ Chronic kidney disease $\cdot$

Oxidative stress $\cdot$ Atubular glomeruli $\cdot$ Vitamin D

\begin{abstract}
There is compelling evidence that interstitial inflammation plays a central role in the loss of renal function in chronic renal disease. The combined effects of interstitial inflammation, oxidative stress and local angiotensin II activity result in the disruption of glomerulus-tubule continuity, the development of pathogenic hypoxia, the generation of myofibroblasts and fibrosis, and the impairment of the protective autoregulation of glomerular blood flow that leads to glomerulosclerosis. The association between proteinuria and progression of chronic kidney disease is firmly established. Proximal tubular cells (PTC) exposed to high concentration of proteins produce proinflammatory and profibrotic factors. The activation of nuclear factor $\mathrm{\kappa B}$ and the signal transducer and activator of transcription results in the upregulation of a variety of cytokines and chemokines, overexpression of adhesion molecules and interstitial infiltration of inflammatory cells. Fibrosis is promoted by release of transforming growth factor $\beta$, which induces myofibroblast for-
\end{abstract}

mation and collagen deposition. Finally, the participation of vitamin $\mathrm{D} 3$ deficiency in the development of tubulointerstitial fibrosis is reviewed. The molecule $1,25-(\mathrm{OH})_{2} \mathrm{D}_{3}$ modulates PTC proliferation, suppresses fibroblast activation and matrix production, reduces epithelial mesenchymal transition and downregulates the genes of the renin-angiotensin system, which are critical steps in the development of a scarred kidney.

Copyright $\odot 2010$ S. Karger AG, Basel

\section{Tubulointerstitial Damage and Renal Function}

The participation of tubulointerstitial lesions in the loss of kidney function was tacitly recognized since the availability of kidney biopsy made it possible to examine diseased kidneys before the development of end-stage renal injury. However, it was nearly 4 decades ago when Risdon et al. [1] reported that the severity of tubular damage had a more significant correlation with the reduction in creatinine clearance than glomerular damage scores. In subsequent studies, Bohle et al. [2] confirmed the association between tubulointerstitial fibrosis and renal function and extended these observations to immunoglobulin A nephropathy, poststreptococcal glomerulo-

\section{KARGER}

Fax +4161306 1234 E-Mail karger@karger.ch www.karger.com
() 2010 S. Karger AG, Basel

$1660-2110 / 10 / 1162-0081 \$ 26.00 / 0$

Accessible online at:

www.karger.com/nec
Bernardo Rodríguez-Iturbe

Servicio de Nefrología, Hospital Universitario de Maracaibo

Ave Goajira s/n

Maracaibo 4001-A (Venezuela)

Tel. +58 261751 9610, Fax +58 261752 4838, E-Mail bernardori@telcel.net6.ve 
Fig. 1. a Pathways of tubulointerstitial inflammation leading to end-stage renal disease. The combined effects of inflammation, oxidative stress and intrarenal angiotensin II activity produce interstitial capillary loss, tubular encroachment and disconnection from the glomeruli, afferent arteriolopathy, cytokine-induced loss of autoregulatory capacity of glomerular blood flow and remodeling of glomerular arterioles. Structural alterations $(\mathbf{b}, \mathbf{c})$ are emphasized with a light grey background in the diagram (brown in the online version). AII = Angiotensin II; ROS $=$ reactive oxygen species; EMT = epithelial mesenchymal transdifferentiation; SNGFR = single nephron glomerular filtration rate; SNBF = single nephron blood flow. $\mathbf{b}$ Intense inflammatory reactivity originating from a segment of adhesion of the glomerular tuft to the Bowman's capsule (arrowhead). The inflammation has constricted the corresponding tubule (indicated by ${ }^{*}$ ) that shows dilatation and atrophy. c Remodeling and increased media thickness in arterioles surrounded by inflammatory infiltrate in the proximity of the glomeruli with segmental sclerosis.
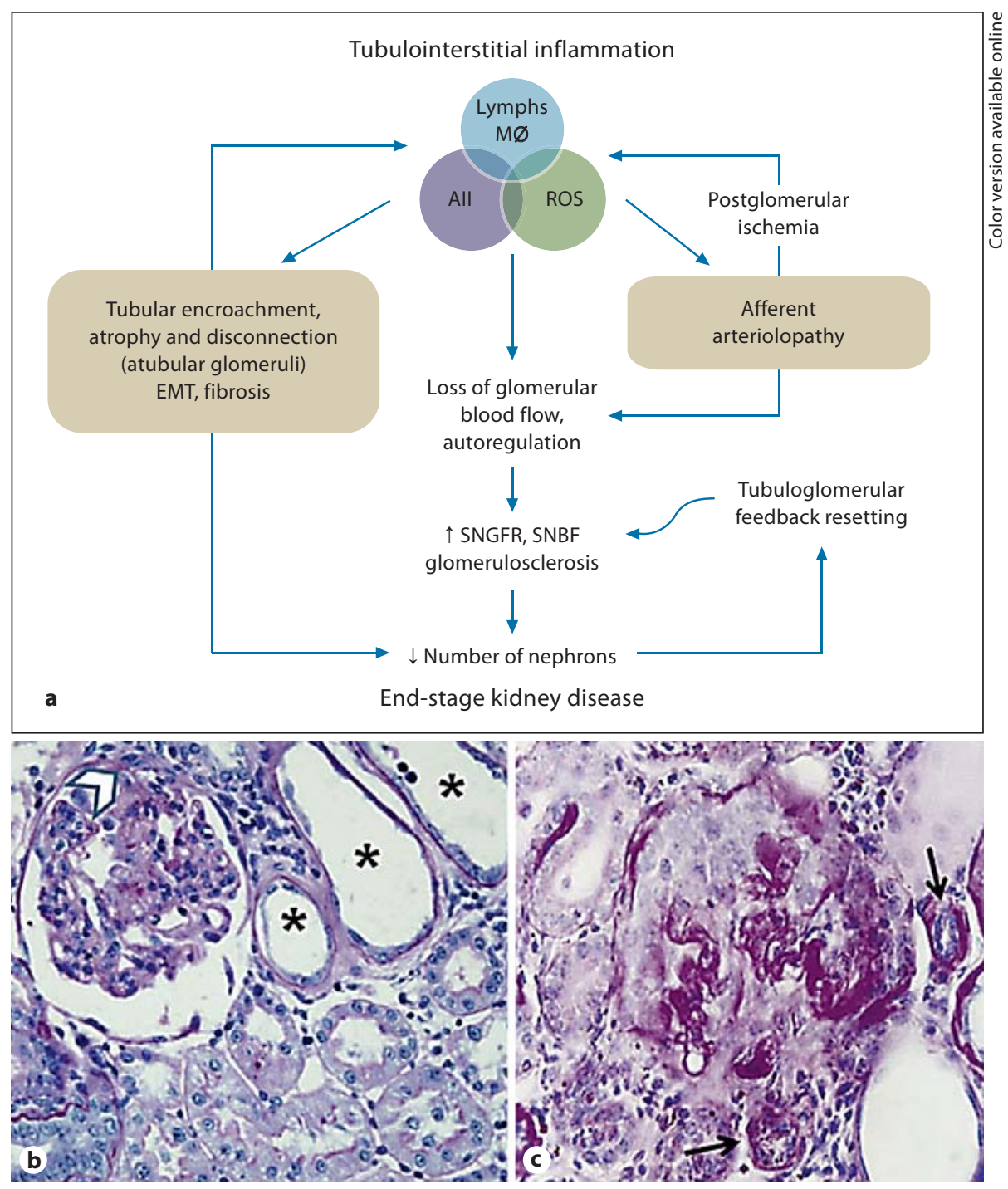

nephritis, mesangial proliferative glomerulonephritis, membranoproliferative glomerulonephritis, focal segmental glomerulosclerosis, and membranous nephropathy. Not only were the increments in interstitial volume and fibrosis reported to be correlated with renal functional impairment and worse prognosis, but also the reduction in peritubular capillaries, the morphological changes in tubular epithelia and the intensity of inflammatory infiltration in the interstitium correlated with renal functional deterioration.

Why the severity of tubulointerstitial disease should be better correlated with renal function and prognosis is not intuitively obvious. It may be due to the fact that in renal biopsies the tubulointerstitial areas are more representative of the extent of the kidney damage and less subject to sample bias than glomeruli, because segmental changes may be missed in a given glomeruli by the biopsy section. Furthermore, atubular glomeruli may show relative integrity while the disconnected tubule is regularly atrophic and surrounded by inflammatory infiltrate and fibrosis and therefore more indicative of a nonfunctioning nephron.

Notwithstanding the considerations of sampling representativeness, and the fact that the association between interstitial inflammation (defined here as the accumulation of immunocompetent cells) and the chronic renal disease of any etiology [3] does not represent a proof of causality, the improvement resulting from therapies that directly or indirectly reduce the inflammatory infiltration strongly suggests a pathogenic role of inflammation in the development of a chronically scarred kidney. 
Fig. 2. Hypoxia-induced renal damage. Reduced number of capillaries, postglomerular blood reduction, increased oxygen demand and anemia are responsible for a state of chronic hypoxia that generates oxidative, nitrosative and carbonyl stress. Hypoxia stimulates HIF that is enzymatically hydroxylated by the prolyl hydroxylases (PHD1, 2 and 3) and degraded rapidly by the proteasome. Nonhydroxylated HIF binds in the nucleus to HIF- $\beta$ and activates genes involved in the adaptive response to hypoxia. PHD activity is inhibited by oxidative stress, thus favoring the HIF- $\beta$ route. Nonspecific inhibition of PHD has adverse effects but disruption of PHD1 induces hypoxic tolerance [modified from 13].

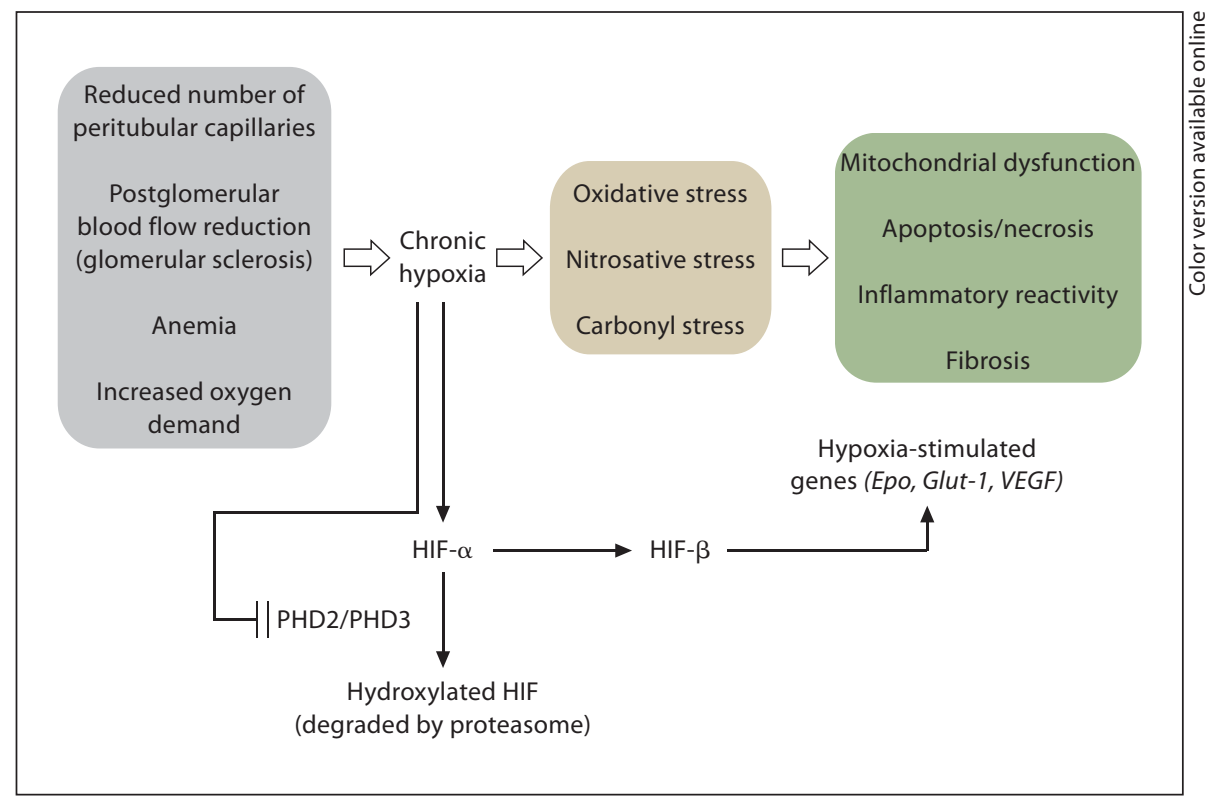

Interstitial inflammation, oxidative stress and local angiotensin II activity are constantly associated [4] and their combined effects result in the disruption of glomerulus-tubule continuity, the development of pathogenic hypoxia and impairment of the protective autoregulation of glomerular blood flow that results in glomerulosclerosis (fig. 1). We shall discuss separately these mechanisms leading to renal scarring, recognizing that, in fact, they complement and support one another and lead to the development of fibrosis by the myofibroblast transformation of vascular pericytes [5] and/or the epithelial mesenchymal transdifferentiation of tubular epithelial cells [6]. This is a process in which transforming growth factor $\beta$ (TGF- $\beta$ ) and matrix metalloproteinase 9-mediated Ecadherin disruption are actively involved [7]. The importance of this process is highlighted by the improvement in renal fibrosis by treatments that suppress epithelial mesenchymal transdifferentiation $[6,8]$.

\section{Interstitial Inflammation and the Loss of Nephron Integrity}

Tubulointerstitial inflammation may result from leakage of filtered urine to the interstitial space through capsular adhesions. The works of Kriz and LeHir [9] have exquisitely shown the formation of bridges between podocytes and the Bowman's capsule in sites of capsular adhesions and a remaining narrow urinary space allows leakage of ultrafiltrate to tubulointerstitial areas. Periglomerular inflammation and fibrosis encroach the tubule, which results in tubular atrophy and eventual disconnection from its glomeruli and the formation of atubular glomeruli and aglomerular tubular remnants (fig. 1b). Angiotensin II is critically involved in this process since angiotensin-converting enzyme inhibitors prevent the formation of atubular glomeruli; a protective effect not observed with $\mathrm{Ca}$ antagonists despite lowering blood pressure to a comparable degree [10]. The significance of these structural changes were highlighted in the studies of Gandhi et al. [11] who showed in the remnant kidney model that 25 weeks after renal ablation, only $26 \%$ of the glomeruli have a normal connecting tubule and atubular glomeruli may represent $15-21 \%$ of the glomeruli that have some degree of sclerosis.

\section{Tubulointerstitial Inflammation and Oxidative Stress}

The role of hypoxia in the progression of chronic renal damage was postulated by Fine and Norman [12] who noted that tubulointerstitial inflammation and fibrosis were associated with loss of peritubular capillaries and proposed that hypoxia was a common denominator in chronic kidney damage. As recently reviewed $[12,13]$, the hypoxic milieu would be enhanced by an increment in vasoconstricting (or a reduction in vasodi- 


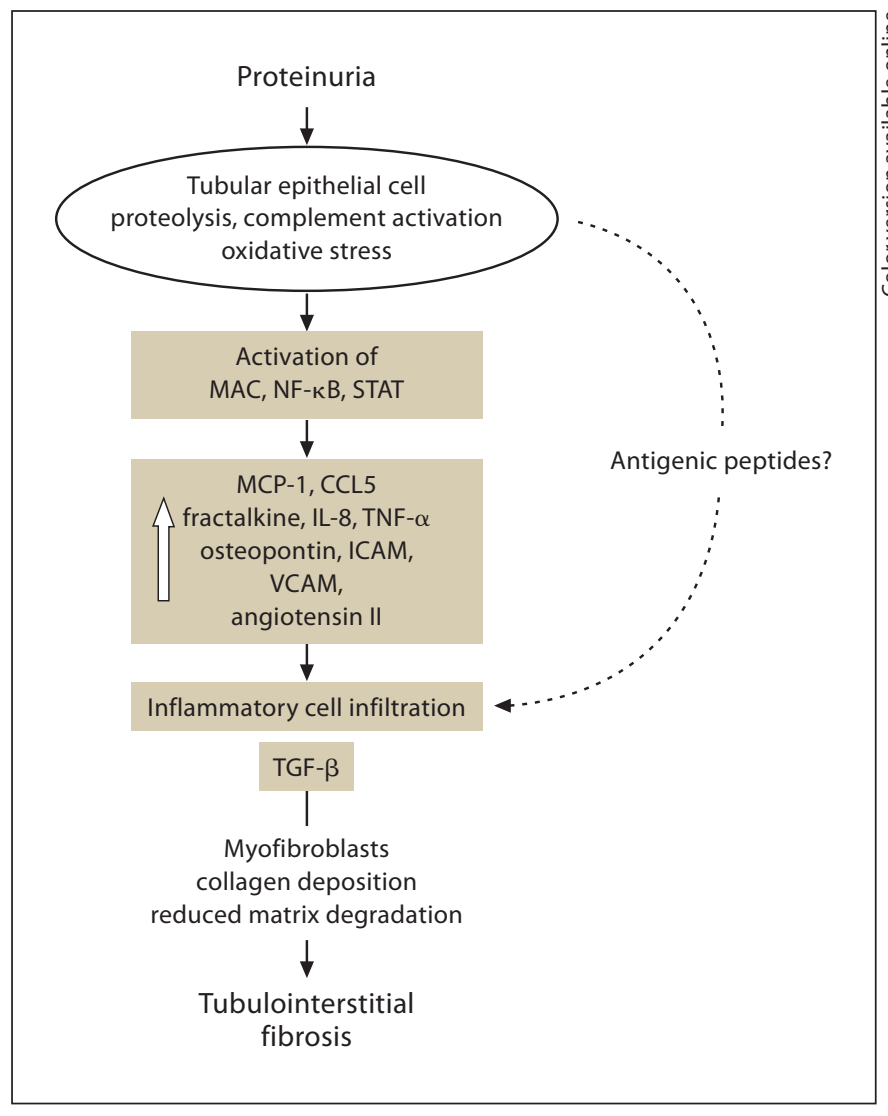

Fig. 3. Activation of inflammatory and fibrogenic pathways in PTC by proteinuria. Proteinuria is assumed to induce chronic renal damage because of the demonstration that is capable to activate growth factors and proinflammatory cytokines in proximal epithelial cells (shown with a shaded background) as described in the text. $\mathrm{MAC}=$ Membrane attack complex; ICAM = intercellular adhesion molecule; VCAM = vascular cell adhesion molecule; IL-8 = interleukin-8.

lating) mediators, increased metabolic demands of hyperfunctioning remnant nephrons and anemia. As inflammation and fibrosis develops, the ongoing structural changes and the increased distance between tubular cells and peritubular capillaries will further impair diffusion and further augment the oxygen deficit. Hypoxia is a potent stimulus for the development of proinflammatory mediators, the increase of myofibroblast population and collagen deposition, and reduced matrix degradation [14]. Miyata and de Strihou [15] have recently reviewed the mechanisms of oxidative stress, nitrosative stress and carbonyl stress resulting from hypoxia, emphasizing the protective role of hypoxia inducible factor (HIF) and the modulation of this response by prolyl hydroxylases (fig. 2). Inhibition of these oxygen- sensing molecules has resulted in an improvement of renal disease in experimental models of diabetic nephropathy and acute renal failure.

\section{Tubulointerstitial Inflammation and Glomerular Blood Flow Autoregulation}

The role played by the loss of the capacity to autoregulate the glomerular capillary blood flow to protect the glomeruli from the effects of systemic hypertension has been extensively studied by Bidani and Griffin [16]. In studies in the remnant kidney model, they demonstrated that the loss of a large number of functioning units results in the impairment of glomerular flow autoregulation. A linear relationship between systemic and glomerular capillary pressure is the consequence of the suppression of this adaptive response and therefore, a large reduction in systemic blood pressure is necessary to protect against hemodynamically-induced glomerulosclerosis. It should be realized that in the renal ablation model, the tubuloglomerular feedback is reset upwards in relation to the extension of renal ablation and is directed to sustain the glomerular hypertension and hyperfiltration (fig. 1), thus contributing to the 'adaptive and potentially maladaptive' responses of nephron loss [17].

An important contribution to the understanding of the relationship between tubulointerstitial inflammation and glomerular damage was offered by Sánchez-Lozada et al. [18] who demonstrated that the accumulation of inflammatory cells in tubulointerstitial areas was associated with proliferative phenotypical changes in afferent arterioles (fig. 1c) that result in rearrangement of extracellular matrix proteins and reduction in the response of vascular smooth muscle cells to contractile stimuli [19]. In addition to structural changes, inflammatory cytokines impair glomerular blood flow autoregulation, as demonstrated by the inhibition of both the proximal (myogenic) and distal (tubuloglomerular feedback) afferent arteriolar vasoconstriction by TGF- $\beta$ in a dose-dependent manner [20].

Taken together, the studies discussed above give a mechanistic explanation for the lower blood pressure target levels currently considered optimal in the treatment of chronic kidney disease (CKD) when physiologic glomerular blood flow autoregulation is impaired or absent. 


\section{Proteinuria and Tubulointerstitial Injury}

While the inflammation resulting from misdirected glomerular filtrate through capsular adhesions is a wellaccepted cause of tubular encroachment and atrophy, the possibility that fibrosis and destruction of nephron architecture may be a consequence of the interstitial inflammatory cell accumulation induced by intense proteinuria is disputed by some investigators [9]. Nevertheless, proximal tubular cells (PTC) exposed to high concentration of proteins change their phenotype and produce proinflammatory and profibrotic factors $[10,21]$. Proteinuriainduced tubulointerstitial inflammation plays a role in the development of salt-sensitive hypertension [21] and there is compelling evidence of the association between the severity of proteinuria and the rate of progression of CKD [22-24].

Proteinuria results in the upregulation of a large number of genes [25] generated by the PTC in response to the uptake of proteins. Megalin, the albumin-binding receptor, is subject to regulated intramembrane proteolysis that links protein reabsorption to gene regulation [26]. Figure 3 presents the proinflammatory effects resulting from the acute exposure of PTC to albumin. Critical in the proinflammatory response to albumin are the activation of nuclear factor $\kappa \mathrm{B}(\mathrm{NF}-\kappa \mathrm{B})$ and the signal transducer and activator of transcription or STAT that are in turn responsible for the upregulation of a variety of cytokines and chemokines, and adhesion molecule overexpression. Protein kinase pathways stimulated by the generation of reactive oxygen species play a central role in the activation of these transcription factors [27]. The role of NF- $\kappa B-i n-$ duced upregulation of macrophage chemotactic factor 1 or MCP-1 and CCL5 (regulated upon activation, normal Tcell expressed, and secreted, or RANTES) are critically important. The role of CCL5 has been studied in experiments that suppressed the NF- $\mathrm{KB}$ activation by intrarenal injection of recombinant adenovirus expressing a truncated form of IкB $\alpha$ [28] and by DNA vaccination with naked DNA encoding for MCP1-1 and CCL5. These strategies, as well as the blockade of chemokine receptor-1 [29], have resulted in the amelioration of inflammatory infiltration, reduction of renal damage, and the slowing of renal scarring.

Complement activation products in the urine contribute to tubulointerstitial inflammation (fig. 3). C6-deficient rats are partially protected from tubular damage, and inhibition of complement activation and formation of membrane attack complex [30] offer protection against tubulointerstitial injury. However, local C3 synthesis by the PTC is unrelated to the development of proteinuria [31].
Table 1. Anti-inflammatory interventions that ameliorate experimental nonimmune chronic renal disease

\begin{tabular}{|c|c|}
\hline Intervention & Disease model \\
\hline $\begin{array}{l}\text { RAS suppression } \\
\text { (ACE inhibitors }{ }^{1}, \text { ARBs } \\
\text { blockers }^{1} \text {, angiotensinogen } \\
\text { antisense mRNA, aliskerin) }\end{array}$ & $\begin{array}{l}\text { Many animal models; transgenic } \\
\text { Ren2 rat, aging nephropathy }\end{array}$ \\
\hline Mycophenolate mofetil & $\begin{array}{l}\text { Remnant kidney, obese Zucker } \\
\text { rat, IRI, lead nephropathy, } \\
\text { diabetic nephropathy }\end{array}$ \\
\hline Rapamycin & $\begin{array}{l}\text { Remnant kidney, diabetic } \\
\text { nephropathy, PKD }\end{array}$ \\
\hline 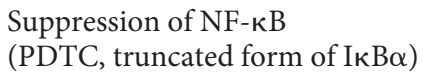 & Remnant kidney \\
\hline $\begin{array}{l}\text { DNA vaccination for CCL2, } \\
\text { CCL5 }\end{array}$ & Adriamycin-induced nephropathy \\
\hline Blockade of CCR-1 receptor & $\begin{array}{l}\text { UUO, Adriamycin-induced } \\
\text { nephropathy }\end{array}$ \\
\hline NO donors & $\begin{array}{l}\text { Remnant kidney, } \\
\text { diabetic nephropathy, PAN }\end{array}$ \\
\hline
\end{tabular}

Antioxidants (melatonin, niacin) Remnant kidney

PDE5 inhibition (sildenafil) Remnant kidney, IRI, CyA toxicity

HIF activation (suppression of IRI, remnant kidney,

prolyl hydroxylases by cobalt cisplatin toxicity

chloride and other strategies)

\begin{tabular}{ll}
\hline COX inhibitors & Diabetic nephropathy, IRI, PKD \\
\hline IL-10 gene therapy & Remnant kidney \\
\hline Vitamin D analogs & Remnant kidney \\
\hline Erythropoietin & $\begin{array}{l}\text { Remnant kidney, IRI, toxicity by } \\
\text { cisplatin, CyA and radiocontrasts, } \\
\text { UUO }\end{array}$ \\
\hline Statins & UUO, Imai rat \\
\hline PPAR- $\gamma$ agonists & Remnant kidney, PAN
\end{tabular}

Interventions that directly or indirectly have been found to suppress inflammation and improve renal disease in specified experimental model (references available upon request).

RAS = Renin-angiotensin system; $\mathrm{ACE}=$ angiotensin-converting enzyme; $\mathrm{ARB}=$ angiotensin receptor blockers; $\mathrm{PDTC}=$ pyrrolidine dithiocarbamate; CCL2 = MCP1 (macrophage chemotactic factor); CCL5 = RANTES; CCR-1 = chemokine receptor-1; UUO = unilateral ureteral obstruction; $\mathrm{NO}=$ nitric oxide; $\mathrm{PAN}=$ puromycin aminonucleoside nephrosis; PDE5 = phosphodiesterase 5; IRI = ischemia-reperfusion injury; $\mathrm{CyA}=$ cyclosporin $\mathrm{A}$; $\mathrm{COX}=$ cyclooxygenase; $\mathrm{PKD}=$ polycystic kidney disease; $\mathrm{IL}=$ interleukin; PPAR- $\gamma=$ peroxisome proliferator-activated receptor gamma.

${ }^{1}$ Used successfully in humans. 
Despite the evidence that abnormal protein trafficking may damage the tubulointerstitium, the actual component of the filtered protein that carries the nephrotoxic potential still is unknown. One factor may be the association with lipids that accompany heavy albuminuria, especially in nephrotic syndrome. The addition of oleic acid markedly increases the inflammatory potential of bovine serum albumin [32]. Fatty acids activate peroxisome proliferator-activated receptors in a dosedependent manner which results in apoptosis of PTC [33], suggesting that these elements are critical determinants of tubular atrophy [34]. The angiotensin AT2 receptor is involved in the apoptosis in PTC in chronic overload proteinuria [35]. Another factor that could have nephrotoxic potential is the generation of antigenic peptides resulting from proteasomal processing of reabsorbed albumin [36].

\section{Vitamin D and Tubulointerstitial Fibrosis}

Recent investigations have demonstrated the participation of vitamin D deficiency in the development of tubulointerstitial fibrosis. The PTC is the site of endogenous synthesis of $1,25-(\mathrm{OH})_{2} \mathrm{D}_{3}$. The recovery of $25-(\mathrm{OH})$ $\mathrm{D}_{3}$ from the urine by megalin-facilitated endocytosis is hampered by a reduction of functioning renal mass.

Apart from its classical role in bone and mineral metabolism, 1,25- $(\mathrm{OH})_{2} \mathrm{D}_{3}$ has recently been shown to modulate PTC proliferation [37]. In addition, vitamin $\mathrm{D}_{3}$ suppresses fibroblast activation and matrix production, an effect mediated by upregulation of hepatocyte growth factor gene expression and receptor phosphorylation in renal fibroblasts [38]. 1,25- $(\mathrm{OH})_{2} \mathrm{D}_{3}$ reduces epithelial mesenchymal transition by decreasing vitamin $\mathrm{D}$ recep- tor and Smad 3 protein levels and inhibition of $\beta$-catenin signaling, which are critical steps in TGF- $\beta$-mediated myofibroblast generation [39]. The beneficial effects of $1,25-(\mathrm{OH})_{2} \mathrm{D}_{3}$ in chronic renal disease are evidenced by the demonstration that, in the renal obstruction model, treatment with paracalcitol suppressed renal RANTES and tumor necrosis factor- $\alpha$ expression, inhibited renal infiltration of $\mathrm{T}$ cells and macrophages, reduced the accumulation of fibronectin and type I and type III collagen, and ameliorated the expression of $\alpha$-smooth muscle actin, vimentin, and Snail1 [40]. Finally, vitamin $\mathrm{D}_{3}$ downregulates the genes of the renin-angiotensin system that is critically involved in the development of a scarred kidney [41].

In conclusion, we have summarized mechanisms related to tubulointerstitial inflammation that may be involved in the progression of renal damage. These mechanisms may act in combination but their role in the progressive scarring of the kidney has not been fully elucidated. Each one in isolation provides insufficient explanation for chronic renal disease progression; tubular encroachment by misdirected filtrate does not extend to adjacent nephrons [5], interstitial accumulation of macrophages and lymphocytes in the overload proteinuria model does not lead to chronic renal damage [42] and long-standing proteinuria in cubilin-deficient patients (Imerslund-Gräsbeck syndrome) is not associated with renal functional impairment [43]. Nevertheless, as shown in table 1 , many interventions addressed to mechanisms discussed in this review have proven beneficial in models of nonimmune experimental renal disease. The suppression of the renin-angiotensin system is a modality that has already been used successfully in humans, while the rest represents a variety of approaches with potential clinical significance.

\section{References}

$\checkmark 1$ Risdon RA, Sloper JC, de Wardener HE: Relationship between renal function and histological changes found in renal-biopsy specimens from patients with persistent glomerular nephritis. Lancet 1968;2:363366.

-2 Bohle A, Mackensen-Haen S, von Gise H, Grund KE, Wehrmann M, Batz C, Bogenschütz O, Schmitt H, Nagy J, Müller C, Müller G: The consequences of tubulo-interstitial changes for renal function in glomerulopathies. A morphometric and cytological analysis. Pathol Res Pract 1990;186:135-144.

\footnotetext{
-3 Rodríguez-Iturbe B, Pons $\mathrm{H}$, Herrera-Acosta J, Johnson RJ: The role of immunocompetent cells in non-immune renal diseases. Kidney Int 2001;59:1626-1640.

-4 Rodriguez-Iturbe B, Johnson RJ, HerreraAcosta J: Tubulointerstitial damage and progression of renal failure. Kidney Int 2005; 68(suppl 99):S82-S86.

-5 Lin SL, Kisseleva T, Brenner DA, Duffield JS: Pericytes and perivascular fibroblasts are the primary source of collagen-producing cells in obstructive fibrosis of the kidney. Am J Pathol 2008;173:1617-1627.
}

\footnotetext{
6 Iwano M, Plieth D, Danoff TM, Xue C, Okada H, Neilson EG: Evidence that fibroblasts derive from epithelium during tissue fibrosis. J Clin Invest 2002;110:341-350.

7 Tan TK, Zheng G, Hsu TT, Wang Y, Lee VW, Tian X, Wang Y, Cao Q, Wang Y, Harris DC: Macrophage matrix metalloproteinase-9 mediates epithelial-mesenchymal transition in vitro in murine renal tubular cells. Am J Pathol 2010, E-pub ahead of print.

8 Liu Y: Renal fibrosis: new insights into the pathogenesis and therapeutics. Kidney Int 2006;69:213-217.
} 
$\checkmark 9$ Kriz W, LeHir M: Pathways to nephron loss starting from glomerular diseases: insights from animal models. Kidney Int 2005;67: 404-419.

-10 Benigni A, Gagliardini E, Remuzzi A, Coma D, Remuzzi G: Angiotensin-converting enzyme inhibition prevents glomerular-tubule disconnection and atrophy in passive Heyman nephritis, an effect not observed with a calcium antagonist. Am J Pathol 2001;159: 1743-1750.

-11 Gandhi M, Olson JL, Meyer TW: Contribution of tubular injury to loss of remnant kidney function. Kidney Int 1998;54:1157-1165.

-12 Fine LG, Norman JT: Chronic hypoxia as a mechanism of progression of chronic kidney diseases: from hypothesis to novel therapeutics. Kidney Int 2008;74:867-872.

-13 Nangaku M: Chronic hypoxia and tubulointerstitial injury: a final common pathway to end stage renal failure. J Am Soc Nephrol 2006; 17:17-25.

14 Eddy AA: Progression in chronic kidney disease. Adv Chronic Kidney Dis 2005;12:353365.

15 Miyata T, de Strihou CY: Diabetic nephropathy: a disorder of oxygen metabolism? Nat Rev Nephrol 2009;6:1-13.

-16 Bidani AK, Griffin KA: Pathophysiology of hypertensive renal damage: implications for therapy. Hypertension 2004;44:595-601.

17 Salmond R, Seney FD: Reset tubuloglomerular feedback permits and sustains glomerular hyperfunction after extensive renal ablation. Am J Physiol 1991;260:F395-F401.

-18 Sánchez-Lozada G, Tapia E, Johnson RJ, Rodriguez-Iturbe B, Herrera-Acosta J: Glomerular hemodynamic changes associated with arteriolar lesions and tubulointerstitial inflammation. Kidney Int 2003;64(suppl 86): S9-S14.

-19 Touyz RM, He G, El Mabroul M, Schiffrin EL: p38 MAP kinase regulates vascular smooth muscle cell collagen synthesis by angiotensin II in SHR but not in WKY. Hypertension 2001;37:574-580.

20 Sharma K, Cook A, Smith M, Valancius C, Inscho EW: TGF-beta impairs renal autoregulation via generation of ROS. Am J Physiol Renal Physiol 2005;288:F1069-F1077.

-21 Alvarez V, Quiroz Y, Nava M, Pons H, Rodriguez-Iturbe B: Overload proteinuria is followed by salt-sensitive hypertension caused by renal infiltration of immune cells. Am J Physiol Renal Physiol 2002;283:F1132F1141.
22 Remuzzi G: Nephropathic nature of proteinuria. Curr Opin Nephrol Hypertens 1999;8: 655-663.

23 D’Amico G, Bazzi C: Pathophysiology of proteinuria. Kidney Int 2003;63:809-825.

24 Iseki K, Ikemiya Y, Iseki C, Takishita S: Proteinuria and the risk of developing end-stage renal disease. Kidney Int 2003;63:1468-1474.

25 Nakajima H, Takenaka M, Kaimori JY, Nagasawa Y, Kosugi A, Kawamoto S, Imai E, Hori M, Okubo K: Gene expression profile of renal proximal tubules regulated by proteinuria. Kidney Int 2002;61:1577-1587.

26 Biemesderfer D: Regulated intramembrane proteolysis of megalin: linking urinary protein and gene regulation in proximal tubule? Kidney Int 2006;69:1717-1721.

$\checkmark 27$ Morigi M, Macconi D, Zoja C, Donadelli R, Buelli S, Zanchi C, Ghilardi M, Remuzzi G: Protein overload-induced NF- $\mathrm{KB}$ activation in proximal tubular cells requires $\mathrm{H}(2) \mathrm{O}(2)$ through a PKC-dependent pathway. J Am Soc Nephrol 2002;13:1179-1189.

28 Takase O, Hirahashi J, Takayanagi A, Chikaraishi A, Marumo T, Ozawa Y, Hayashi M, Shimizu N, Saruta T: Gene transfer of truncated IкB $\alpha$ prevents tubulointerstitial injury. Kidney Int 2003;63:501-513.

29 Anders HJ, Ninichuk V, Schöndorff D: Progression of kidney disease: blocking leukocyte recruitment with chemokine receptor CCR1 antagonists. Kidney Int 2006;69:2932.

30 He C, Imai M, Song H, Quigg RJ, Tomlinson $\mathrm{S}$ : Complement inhibitors targeted to the proximal tubule prevent injury in experimental nephritic syndrome and demonstrate a key role for C5b-9. J Immunol 2005;174: 5750-5757.

-31 Noris M, Morigi M, Remuzzi B: Complement-mediated dysfunction of glomerular filtration barrier accelerates progressive renal injury. J Am Soc Nephrol 2008;19:11581167.

-32 Van Timmeren MM, Bakker SJ, Stegeman CA, Gans RO, van Goor H: Addition of oleic acid to delipidated bovine serum albumin aggravates renal damage in experimental protein-overload nephrosis. Nephrol Dial Transplant 2005;20:2349-2357.

33 Arici M, Chana R, Lewington A, Brown J, Brunskill NJ: Stimulation of proximal tubular cell apoptosis by albumin-bound fatty acids mediated by peroxisome proliferator activated receptor- $\gamma$. J Am Soc Nephrol 2003; $14: 17-27$.
34 Morais C, Westhuyzen J, Metharom P, Healy $\mathrm{H}$ : High molecular weight plasma proteins induce apoptosis and Fas/FasL expression in human proximal tubular cells. Nephrol Dial Transplant 2005;20:50-58.

-35 Tejera N, Gomez-Garre D, Lazaro A, Gallego-Delgado J, Alonso C, Blanco J, Ortiz A, Egido J: Persistent proteinuria up-regulates angiotensin II type 2 receptor and induces apoptosis in proximal tubular cells. Am J Pathol 2004;164:1817-1826.

36 Macconi D, Chiabrando C, Schiarea S, Aiello S, Cassis L, Gagliardini E, Noris M, Buelli S, Zoja C, Corna D, Mele C, Fanelli R, Remuzzi G, Benigni A: Proteasomal processing of albumin by renal dendritic cells generates antigenic peptides. J Am Soc Nephrol 2009;20: 123-130.

37 Weinreich Z, Müller A, Wüthrich RP, Booy C, Binswanger U: 1,25-Dihydroxyvitamin $\mathrm{D}_{3}$ and the synthetic vitamin $\mathrm{D}$ analogue, $\mathrm{KH} \mathrm{1060,} \mathrm{modulate} \mathrm{the} \mathrm{growth} \mathrm{of} \mathrm{mouse}$ proximal tubular cells. Kidney Blood Press Res 1996;19:325-331.

38 Li Y, Spataro BC, Yang J, Dai C, Liu Y: 1,25-Dihydroxyvitamin $\mathrm{D}_{3}$ inhibits renal interstitial myofibroblast activation by inducing hepatocyte growth factor expression. Kidney Int 2005;68:1500-1510.

39 Aschenbrenner JK, Sollinger HW, Becker $\mathrm{BN}$, Hullet DA: $1,25-(\mathrm{OH})_{2} \mathrm{D}_{3}$ alters the transforming growth factor $\beta$ signaling pathway in renal tissue. J Surg Res 2001;100: 171-175.

40 Tan X, He W, Liu Y: Combination therapy with paricalcitol and trandolapril reduces renal fibrosis in obstructive nephropathy. Kidney Int 2009;76:1248-1257.

41 Freundlich M, Quiroz Y, Zhang Z, Zhang Y, Bravo Y, Weisinger JR, Li YC, RodriguezIturbe B: Suppression of renin-angiotensin gene expression in the kidney by paricalcitol. Kidney Int 2008;74:1394-1402.

42 Kikuchi H, Kawachi H, Ito Y, et al: Severe proteinuria, sustained for 6 months, induces tubular epithelial cell injury and cell infiltration in rats but not progressive interstitial fibrosis. Nephrol Dial Transplant 2000;15: 799-810.

43 Wahlstedt-Fröberg V, Pettersson T, Aminoff M, Dugué B, Gräsbeck R: Proteinuria in cubilin-deficient patients with selective vitamin $B_{12}$ malabsorption. Pediatr Nephrol 2003;18:417-421. 


\section{Editorial Comment}

M. El Nahas, Sheffield

The article by Bernardo Rodríguez-Iturbe and Guillermo García García follows in the footsteps of pioneering observations by Risdon and De Wardener (UK) in the 1960s and Bohle (Germany) throughout the 1980s by stressing the key role of tubulointerstitial inflammation and fibrosis in the progression of chronic kidney disease

Since these initial observations, mechanistic hypotheses have been put forward by Bertani and Remuzzi (the nephrotoxicity of albuminuria), Fine and Norman (the nephrotoxicity of hypoxia) and Strutz and Nielson (the epithelial mesenchymal transformation of renal tubules cells), to name a few. The current review updates the reader on a number of such mechanistic pathways but also introduces new potential modulators of renal fibrosis such as vitamin $\mathrm{D}_{3}$. It is over 40 years since the initial observation of Risdon and De Wardener, though a huge body of research mechanisms are unraveling. It is hoped that the next 10 years will see some clinical translation of promising experimental observations to prevent progressive renal fibrosis. 